\section{Gamma Radiation Influences Postharvest Disease Incidence of Pineapple Fruits}

\author{
M. Damayanti, G.J. Sharma', and S.C. Kundu \\ Department of Life Sciences, Manipur University, Imphal-795003, India
}

Additional index words. Ananas comosus, Ceratocystis paradoxa, Penicillium

purpurogenum, gamma irradiation

Abstract. The application of gamma radiation for improving the storage of pineapple fruits [Ananas comosus (L.) Merr. cv. Queen] has been studied in an attempt to reduce decay caused by fungal pathogens such as Ceratocystis paradoxa (Dade)-Moreau and Penicillium purpurogenum Stoll. Gamma radiation at 50, 75, 100, 150, and $250 \mathrm{~Gy}$ improved shelf life. The maximum tolerable dose was $\approx 250 \mathrm{~Gy}$. Fruits irradiated with up to $150 \mathrm{~Gy}$ and then stored at 25 to $28 \mathrm{C}$ maintained their texture better than did the controls. Radiation, particularly at doses $>250 \mathrm{~Gy}$, caused browning of the shin and softening of tissues. Browning increased with increasing radiation dose and storage duration. Excessively high doses promoted spoilage. Doses in the range of $\mathbf{5 0}$ to 250 $\mathrm{Gy}$, in combination with storage at 11 to $13 \mathrm{C}$, can be used to reduce postharvest losses in pineapple due to fungal diseases and senescence, thereby extending shelf life.

A huge quantity of pineapples are lost due to attacks by pathogenic microorganisms during storage. Without some preservative measures the ripe pineapple fruits do not keep well beyond 10 to 12 days.

Gamma radiation can extend the shelf life of many perishable fruits, including pineapple (Urbain, 1986; Zuleta, 1989), by controlling decay caused by pathogenic microorganisms and delaying ripening and senescence. However, a major hindrance to the practical use of radiation for disease control in fresh fruits appears to be that the dose required for effective control of the spoilage pathogens invariably results in damage to the fruit. Doses higher than the maximum tolerable dose cause skin blackening or browning and softening of tissue in oranges [Citrus sinensis (L.) Osb.] and grapefruit (Citrus paradisi Macfad.) (Dennison et al., 1966; Grierson and Dennison, 1965). Shelf life of many fruits is prolonged considerably by the combination of refrigeration and relatively low doses of radiation (i.e., those that do not alter flavor or texture (Thomas, 1987a, 1987b). Information regarding the effect of gamma radiation on the extension of shelf life in pineapple is meager (Urbain, 1986;

Received for publication 3 June 1991. Accepted for publication 13 Jan. 1992. This work is supported by grants from the Dept. of Science and Technology, Government of India, New Delhi (Project no. WS/OO7/86). We thank M.S. Singh for identifying Penicillium purpurogenum and L. Ladu Singh for statistical calculation.

'To whom reprint requests should be addressed.
Zuleta, 1989). We investigated the effect of gamma radiation on postharvest diseases of pineapple fruits harvested during several seasons and determined the optimum dose for extending shelf life during storage.

Healthy, uniformly sized pineapple fruits, weighing 600 to $650 \mathrm{~g}$ each, were harvested $75 \%$ ripe. Extension of shelf life (in days) was determined from this maturity stage until the fruits became dry or infected. About 2 to $3 \mathrm{~cm}$ of the fruit stalk and crown were retained. Fruits were irradiated at $0,50,75$, $100,150,250,500,750$, or 1000 Gy using a $5100-\mathrm{Ci}{ }^{60} \mathrm{Co}-\mathrm{Gamma}$ Irradiator from the Isotopes Division, Bhabha Atomic Research Centre, Bombay, at room temperature within $24 \mathrm{~h}$ of harvest. The racks and storage room had been fumigated with $3 \%$ formaldehyde solution before irradiation of the fruit.

The pathogens causing the postharvest diseases of pineapple fruits were isolated from diseased fruits and grown in potato dextrose

Table 1. Effect of gamma radiation on shelf life in irradiated pineapple fruits (mean value in days).

\begin{tabular}{|c|c|c|c|c|c|c|c|}
\hline \multirow{2}{*}{$\begin{array}{l}\text { Season and } \\
\text { temp }\left({ }^{\circ} \mathrm{C}\right)\end{array}$} & \multicolumn{7}{|c|}{ Dose (Gy) } \\
\hline & 0 & 50 & 75 & 100 & 150 & 250 & 500 \\
\hline Summer (25-28) & 14 & 24 & 26 & 27 & 29 & 25 & 13 \\
\hline Winter (11-14) & 16 & 30 & 32 & 34 & 38 & 42 & 24 \\
\hline Sources of variation & d.f. & & $\begin{array}{l}\text { Sum of } \\
\text { squares }\end{array}$ & \multicolumn{4}{|c|}{$\begin{array}{c}\text { Mean } \\
\text { squares }\end{array}$} \\
\hline Level of radiation & 6 & & 635.06 & \multirow{3}{*}{\multicolumn{3}{|c|}{$\begin{array}{r}105.84 \\
240.70 \\
11.28\end{array}$}} & $9.38^{*}$ \\
\hline Temperature & 1 & & 240.70 & & & & $21.34^{*}$ \\
\hline Error & 6 & & 67.71 & & & & \\
\hline
\end{tabular}

${ }^{*}$ F ratio significant at $P=0.01$. Means for each dose and season based on 100 fruits. agar (PDA) culture medium. Pathogens from these pure cultures were then inoculated on healthy fruits to see whether the same symptoms of disease appeared and to compare the characteristic features of the pathogens isolated from diseased fruits and from the culture medium.

After irradiation, the control and irradiated fruits (three replicates each of 100 fruits per treatment) were stored at room temperature (25 to $28 \mathrm{C}$ ) at $80 \%$ to $85 \%$ relative humidity (RH) in the June-July experiments. Similarly, equal numbers of fruits in each treatment were stored at room temperature (11 to $13 \mathrm{C}$ ) at $70 \%$ to $83 \% \mathrm{RH}$ in December-January.

To check whether infection was due primarily to postirradiation infection, nonirradiated and irradiated fruits $(50,75,100,150$, and $250 \mathrm{~Gy}$ ) were inoculated with agar disks (0.5 cm in diameter) of Ceratocystis paradoxa or Penicillium purpurogenum. These lots were divided into two replicates; one was stored at $25 \pm 1 \mathrm{C}$ and the other at 12 $\pm 1 \mathrm{C}$.

Ceratocystis paradoxa and $P$. pururogenum were identified as the causal organisms responsible for the postharvest diseases of pineapples, $C$. paradoxa being predominant. Ceratocystis paradaxa caused watersoaked areas, and fruit flesh became dark yellow. Affected fruit became soft and it disintegrated under the slightest pressure; juice oozed through the surface. The rot spread rapidly throughout the area round the wound. Badly affected fruits turned black and emitted a characteristic sweetish, ether-like odor. These pathogens have been reported not only in Manipur, but also in other parts of the world (Py et al., 1987; Rangaswami, 1984; Singh, 1982).

Fruits irradiated with doses of 50, 75, 100, or $150 \mathrm{~Gy}$ and then stored at 25 to $28 \mathrm{C}(80 \%$ to $85 \% \mathrm{RH}$ ) maintained their texture (determined as a measure of crushing load) better than the nonirradiated fruits. The maximum tolerable dose was $\approx 250$ Gy. Doses exceeding 250 Gy invariably cause phytotoxicity as 


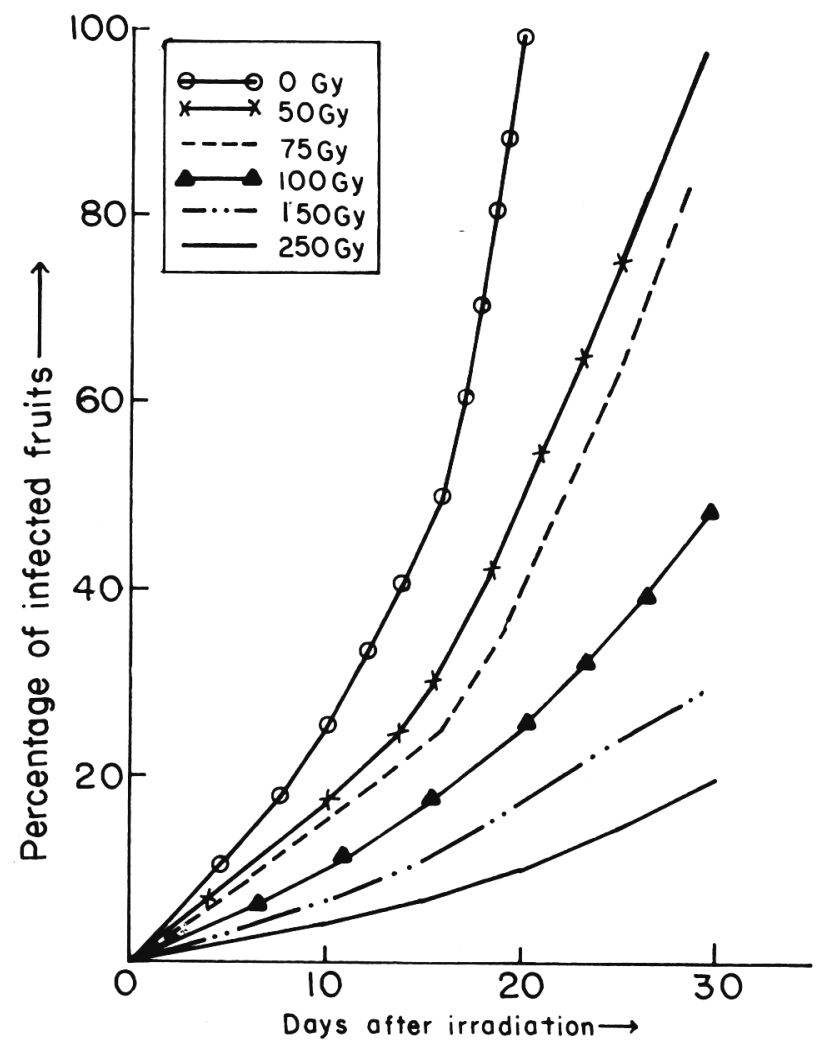

Fig. 1. Effect of gamma radiation on the rate of visible natural infection of pineapple during storage at 25 to $28 \mathrm{C}$ and $80 \%$ to $85 \%$ relative humidity.

manifest by browning; at higher doses, i.e., 750 to $1000 \mathrm{~Gy}$, the extreme browning of the skin and discoloration of crowns made the fruits undesirable. Such fruits also had soft pulp that collapsed on mild application of pressure. The browning and softening were not immediately noticeable after irradiation, but began to appear several days thereafter. This radiation-induced damage to the skin was more severe with increasing radiation dose and time in storage. As the dose was increased beyond $250 \mathrm{~Gy}$, spoilage due to pathogenic microorganisms increased. For fruit harvested in December-January, storage at 11 to $13 \mathrm{C}$ and $70 \%$ to $83 \%$ RH resulted in a longer shelf life of irradiated and nonirradiated-pineapple than that obtained in summer (Table 1). We realize that the effects of harvest season and temperature were not separated in our experiments; thus, the contribution of each factor to the relative lengthening of shelf life cannot be determined from our data. No infection was observed in either irradiated or nonirradiated fruits stored at 11 to $13 \mathrm{C}$ for 30 days. With the increase of radiation dosage up to the maximum tolerable dose (i.e., $250 \mathrm{~Gy}$ ), color change (as observed visually) was slower and freshness was extended.

The number of naturally infected fruits during storage at 25 to $28 \mathrm{C}$ decreased as the dose was increased from 50 to $250 \mathrm{~Gy}$ (Fig. 1). The radiation doses required for effective control of the fungi (C. paradoxa and $P$. purpurogenum) were above $1000 \mathrm{~Gy}$, which was invariably much higher than could be tolerated by the host tissues, i.e., $250 \mathrm{~Gy}$ (Damayanti et al., 1990).

With pineapple fruits artificially inoculated with $C$. paradoxa after irradiation, infection in control fruits was visible within 5 days and the fruit were completely rotten after another 4 to 5 days; fruit irradiated at 50, 75,100 , or $150 \mathrm{~Gy}$ showed no infection up to 5 days and up to 7 days for fruit irradiated with $250 \mathrm{~Gy}$ and held at $25 \pm 1 \mathrm{C}$. With fruits inoculated with $P$ purpurogenum, infection was visible by 7 days at $25 \pm 1 \mathrm{C}$ in nonirradiated fruits, by 8 days in those irradiated at 50 and $75 \mathrm{~Gy}$, and by 9 days in those treated at 100,150 , or $250 \mathrm{~Gy}$. In both pathogens, mycelial growth was completely inhibited with irradiation followed by cold storage (11 to $13 \mathrm{C}$ ) and $70 \%$ to $83 \% \mathrm{RH}$. The inoculum had dried up within 3 days after inoculation without infecting the fruits.

We conclude that gamma radiation at doses of $50,75,100,150$, or 250 Gy in combination with storage at 11 to $13 \mathrm{C}$ and $70 \%$ to $83 \% \mathrm{RH}$ can be used to reduce postharvest losses in pineapples due to fungal diseases caused predominantly by Ceratocystis paradoxa, thereby extending the shelf life of pineapple fruit.

\section{Literature Cited}

Damayanti M., G.J. Sharma, and S.C. Kundu. 1990. Effect of gamma radiation on pineapple fruit rotting- fungus, Ceratocystis paradoxa, at different temperatures. Microbios Lett. 45:145 150

Dennison R.A., W. Grierson, and E.M. Ahmed. 1966. Irradiation of Duncan grapefruit, pineapple and Valencia oranges and Temples. Proc. Fla. State Hort. Soc. 79:285-292.

Grierson, W. and R.A. Dennison. 1965. Irradiation treatment of 'Valencia oranges and 'Marsh' grapefruit. Proc. Fla. State Hort. Soc. 78:233237.

Py, C., J.J. Lacoeuilhe, and C. Teisson. 1987. The pineapple: Cultivation and uses. Techniques Agricoles et Productions Tropicales. G.-P. Maisonneuve et Larose, Paris. p. 205 209.

Rangaswami, G. 1984. Diseases of crop plants in India. 2nd ed. Prentice-Hall, New Delhi, India. p. 374-375.

Singh, R.S. 1982. Plant pathogens-The fungi. Oxford and IBH Publishing Co., New Delhi, India. p. 190-191.

Thomas, P. 1987a. Radiation preservation of foods of plant origin IV. Subtropical fruits: Citrus, grapes and avocados. CRC Critical Rev. Food Sci. Nutr. 24(1):53-89.

Thomas, P. 1987b. Radiation preservation of foods of plant origin V. Temperate fruits: Pome fruits, stone fruits and berries. CRC Critical Rev. Food Sci. Nutr. 24(4):357-400.

Urbain, W.M. 1986. Food irradiation. Academic, London. p. 170-215.

Zuleta, S. 1989. Technical and economic feasibility of irradiating mango and other fruits. Food Irradiation Nwsl. 13(2):27. 